\title{
Repeated Stand-Replacing Crown Fires Affect Seed Morphology and Germination in Aleppo pine
}

\author{
Antonio Saracino ${ }^{1 *}$, Alessandro Bellino ${ }^{1 \dagger}$, Emilia Allevato ${ }^{1}$, Antonio Mingo ${ }^{1}$, \\ Stefano Conti ${ }^{1}$, Sergio Rossi ${ }^{2,3}$, Giuliano Bonanomi ${ }^{1}$, Domenico Carputo ${ }^{1}$ and \\ Stefano Mazzoleni ${ }^{1}$ \\ ${ }^{1}$ Department of Agricultural Sciences, University of Naples Federico II, Portici, Italy, ${ }^{2}$ Département des Sciences \\ Fondamentales, Université du Québec à Chicoutimi, Chicoutimi, QC, Canada, ${ }^{3}$ Key Laboratory of Vegetation Restoration \\ and Management of Degraded Ecosystems, Guangdong Provincial Key Laboratory of Applied Botany, South China Botanical \\ Garden, Chinese Academy of Sciences, Guangzhou, China
}

OPEN ACCESS

Edited by:

Heidi Renninger,

Mississippi State University,

United States

Reviewed by:

Javier Madrigal,

Instituto Nacional de Investigación y

Tecnología Agraria y Alimentaria,

Spain

Leonor Calvo Galvan,

Universidad de León, Spain

*Correspondence:

Antonio Saracino

antonio.saracino@unina.it

${ }^{\dagger}$ Present Address:

Alessandro Bellino,

Department of Chemistry and Biology,

University of Salerno, Salerno, Italy

Specialty section:

This article was submitted to

Functional Plant Ecology,

a section of the journal

Frontiers in Plant Science

Received: 20 December 2016

Accepted: 16 June 2017

Published: 30 June 2017

Citation:

Saracino A, Bellino A, Allevato $E$

Mingo A, Conti S, Rossi S,

Bonanomi G, Carputo $D$ and

Mazzoleni S (2017) Repeated

Stand-Replacing Crown Fires Affect Seed Morphology and Germination in Aleppo pine. Front. Plant Sci. 8:1160.

doi: 10.3389/fpls.2017.01160
Post-fire reproductive niche of Aleppo pine (Pinus halepensis) is deeply interlaced with fire products. Indeed, the high $\mathrm{pH}$ and low osmotic potentials of ash beds under burnt crowns constitute the main constraints to seed germination. In this study, we aim to investigate whether fire recurrence, through the physico-chemical constraints imposed by the ash beds, affects the reproduction ability of $P$. halepensis at the germination stage. To this aim, Aleppo pine seeds were collected in neighboring even-aged stands subjected to 0,1 , or 2 fires (namely fire cohorts), and seed morphology and germination performance, in terms of cumulative germination and germination kinetics, were studied under increasing osmotic potentials (from 0.0 to $-1.2 \mathrm{MPa}$ ) and $\mathrm{pH}$ (from 6 to 11). Besides fire history, the role of ontogenetic age of mother plants on seed morphology and germination was also investigated. Differences in seed morphology among the three cohorts have been highlighted in a multivariate context, with anisotropic enlargement of the seeds produced by pine stands experiencing repeated fires. The patterns of seed germination varied primarily in relation to the fire cohort, with seeds from the pine stand experiencing repeated fires exhibiting enhanced tolerance to $\mathrm{pH}$ stress. Conversely, germination performances under osmotic constraints mainly depends on tree ontogenetic stage, with an involvement of fire history especially in the timing of seed germination. Our results suggest that, at least in the short term, fire recurrence does not constrain the reproduction ability of Aleppo pine. These results highlight the need for further research to elucidate the mechanisms behind these responses to recurrent fires.

Keywords: fire recurrence, Mediterranean, seed germination, seed morphometry, osmotic potential, Pinus halepensis, $\mathrm{pH}$, tree ontogeny

\section{INTRODUCTION}

Fire disturbance plays a crucial role in shaping plant communities and selecting plants with fire-related traits in Mediterranean ecosystems. Perennial, non-resprouting species with post-fire seeding ability (obligate seeders sensu Pausas and Keeley, 2014) are particularly sensitive to the length of fire return intervals, i.e., the time between two successive fires. These species are particularly affected by fires occurring during the immature stage of their life cycle, before seed reserves have built up, or during senescence, when they are already depleted (Zedler, 1995). Serotiny, the late release of ripe seeds from cones or fruits (Lamont et al., 1991), is a peculiar trait 
allowing species to maintain a persistent hanging canopy seed bank, usually accessed in hot and dry conditions generated during fire events or by wind (Nathan et al., 1999; Rossi et al., 2017).

Aleppo pine (Pinus halepensis Miller) is a perennial species that grows mainly in fire-prone areas along the coast and in the interior of the Mediterranean Basin forming, at landscape level, variable patches of single-cohort stands which can locally disappear when fire is absent over a century (Agee, 1998). The species has a very short juvenile phase (Thanos and Daskalakou, 2000; Climent et al., 2008; Espelta et al., 2008), and builds canopy seed banks (Daskalakou and Thanos, 1996) consisting of both serotinous and non-serotinous cones with anatomicallydifferent scales (Moya et al., 2008), whose ratio is dependent on both environmental and ontogenetic factors (Martín-Sanz et al., 2016). During its life cycle, this species progressively modifies the microenvironment to which its offspring are exposed through pre-fire litter production and necromass retention in the crown, which in turn affect fire intensity and post-fire products (Schwilk and Ackerly, 2001). The physical modification of the surroundings by pine trees is an example of niche construction by inceptive perturbation as labeled by Odling-Smee et al. (2003). The post-fire reproductive niche of Aleppo pine is spatially restricted under the crown projection and radially asymmetric for germination, seedling establishment and growth (Ne'eman, 2000). Ontogenetic modification of the crown shape, from conical to umbrella-like across the life cycle (Shmida et al., 2000) progressively increases the crown surface projection from 20 to $90 \mathrm{~m}^{2}$ in trees without crown lateral competition in the old growth stage (Saracino et al., 2002). Low canopy base height (Mitsopoulos and Dimitrakopoulos, 2007, 2014), no selfpruning of dead branches (Keeley and Zedler, 1998; Schwilk and Ackerly, 2001) and no shedding of old open cones (Shmida et al., 2000; Saracino, personal observation) contribute to the propagation of fire from the forest floor up to the crown and an increase in the canopy fuel load. In addition, canopy bulk density actively supports crown fires (Mitsopoulos and Dimitrakopoulos, 2007, 2014). These traits represent a fire-embracing strategy (Schwilk and Ackerly, 2001; Pausas, 2015) aiming to promote the post-fire niche regeneration of Aleppo pine by producing a spatially heterogeneous thickness of ashes (Cerdà and Doerr, 2008).

The intensity of fire affects the quality and quantity of the ashes under the burnt canopy of Aleppo pine trees. Complete plant litter oxidation produces whitish-gray mineral ashes rich in soluble cations (Liodakis et al., 2005), whereas partial oxidation leaves organic components charred, dark and still rich in carbon (Bodí et al., 2014). The ash layer thickness decreases from the stem to the edge of the crown projection, following the radial asymmetry of pre-fire litter accumulation. Increasing ash thickness can inhibit seed germination (Paula et al., 2009) due to the increasing $\mathrm{pH}$ and reduction in osmotic potential (HenigSever et al., 1996). Moreover, repeated stand-replacing crown fires can reduce growth and reproductive fitness due to a delay in the onset of pine reproduction and a reduction in the number of reproductive pines and cone crop per tree (Eugenio et al., 2006; Espelta et al., 2008). By contrast, Ne'eman et al. (2004) and
Goubitz et al. (2004) documented higher levels of serotiny as a positive response to fire.

To sum up, post-fire germination depends on a number of environmental, genetic, and ontogenetic factors which can affect regeneration processes. These factors may be strongly interlaced and it is difficult to assess their role under natural conditions.

In this study we aim to investigate the effect of two main constraints exerted by post-fire substrate conditions, namely osmotic potential and $\mathrm{pH}$, on seed germination both in relation to fire history and ontogenetic age of mother plants. To this end, germination behavior of seeds collected from Aleppo pine cohorts experiencing different fire histories were investigated under simulated conditions of post-fire substrates. Since morphology of the seeds could be involved in germination behavior, a set of morphological traits were also investigated in relation to ontogenetic stage and fire recurrence.

We selected stands located on costal sand dunes in Southern Italy, where the spatially heterogeneous recurrence of summer fires offered a unique opportunity to investigate the role of fire histories under homogeneous environmental conditions.

\section{MATERIALS AND METHODS}

\section{Study Area and Seed Collection}

The study area is located in a native Aleppo pine forest growing on coastal sand dunes in the Biogenetic Natural Reserve Stornara

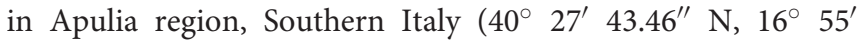
$00.59^{\prime \prime}$ E) (Figure 1). The soil is a loose siliceous-calcareous sand (Dumontet et al., 1996). Pine is associated with evergreen sclerophyllous (Pistacia lentiscus, Phillyrea angustifolia, Myrtus communis, Rhamnus alaternus, Rosmarinus officinalis), and malacophyllous (Cistus salvifolius) shrub species. The climate is semiarid Mediterranean, with a mean annual temperature of $15.8^{\circ} \mathrm{C}$, and total precipitation of $535 \mathrm{~mm}$.

Three patches with different fire histories were selected within the same forest, in order to minimize environmental variability and isolate the role of fire histories. Selection was done by using the fire register of the National Forest Service (since 1960) and fire maps drawn up by means of an aerial photogrammetric chronosequence $(1947,1954,1974,1990,2002)$. In this forest, two stand-replacing crown fires occurred, partially overlapping and forming three patches with different fire history, burning 0, 1, and 2 times (FC0, FC1, and FC2, respectively, Table 1; Figure 1). In FC0, in addition to the analysis of aerial photos, the absence of recent fires was confirmed by the absence of charcoal fragments in the first $40 \mathrm{~cm}$ soil profile. In January 2008, 50-100 cones older than 2 years were collected from the whole perimeter of the middle and upper crown of 10 randomly selected plants from each fire cohort. Tree total height and diameter at breast height were measured, using a Tandem clinometer (Suunto, Finland) and a meter tape, respectively, to be used as a proxy of ontogenetic age, for all sampled trees (Table 1). In order to accurately represent the seed pool accessible during a fire event, both brown and serotinous cones were collected.

Cones from each plant were separately dried over 1 week in a well-ventilated and shaded environment, put in jute bags and moved to an oven ventilated at $50^{\circ} \mathrm{C}$ to facilitate scale shrinkage. 


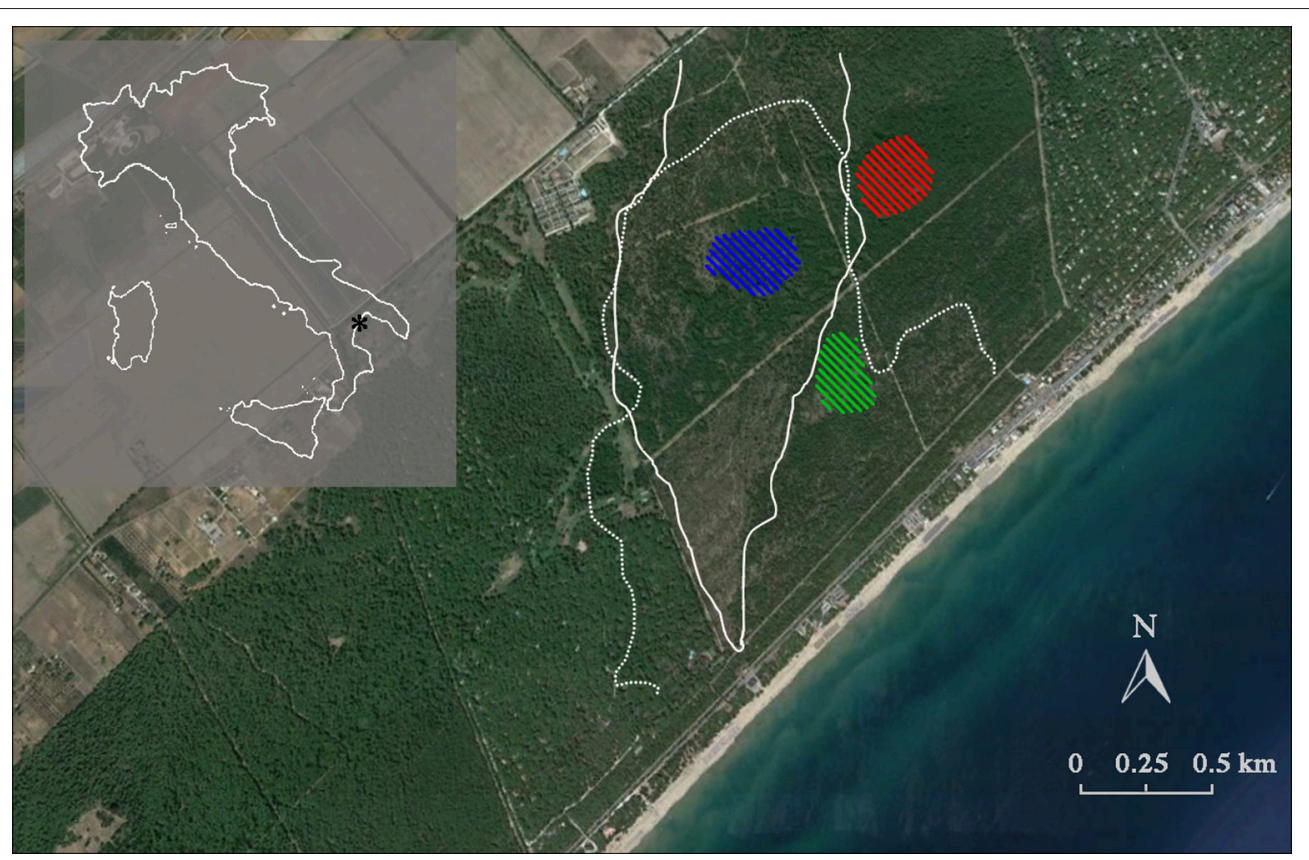

FIGURE 1 | Location of the study site, showing Italy (shaded area) with the relative position of the Biogenetic Natural Reserve Stornara in Apulia region $\left({ }^{\star}\right)$. The native Aleppo pine (Pinus halepensis Miller) forest is registered in the National Book of Seed Forests managed by the Italian Forest Service (MAF, 1960) and is also recognized as a selected seed stand for Aleppo pine of the Mediterranean Basin due to its importance as a germplasm resource (Registration number 52-55, Castellaneta, FAO, 1997). White lines represent the stand-replacing crown fire boundaries (1970: dotted line; 1994: solid line). Diagonal line patterns indicate the tree sampling sites. Red: fire cohort 0 (FC0); green: fire cohort 1 (FC1); blue: fire cohort 2 (FC2).

TABLE 1 | Fires and trees characteristics of the three fires cohorts with different fire history, burning 0,1 , and 2 times (FC0, FC1, and FC2, respectively).

\begin{tabular}{lllcc}
\hline Fire cohorts & Fire dates & \multicolumn{3}{c}{ Tree characteristics } \\
\cline { 3 - 5 } & & DBH (cm) & Height (m) & Age (years) \\
\cline { 3 - 5 } & - & $55.8 \pm 10.1$ & $16.4 \pm 1.2$ & 85 \\
FC0 & July 1970 & $24.5 \pm 2.9$ & $9.0 \pm 0.7$ & 37 \\
FC1 & July 1970 and & $15.9 \pm 4.0$ & $8.4 \pm 1.2$ & 13 \\
FC2 & August 1994 & & & \\
& & & & \\
\hline
\end{tabular}

Values are given as mean \pm s.d. ( $n=10$ for each fire cohort). $D B H$ represent the diameter at breast height.

The seeds extracted were stored in vacuum-type PVC bags at $4^{\circ} \mathrm{C}$. From each of the different fire cohorts at least 1200 seeds for the germination tests and 125-150 for morphometric analysis were used. Seeds from the various plants of each fire cohort were pooled together in the germination experiment, in order to investigate the overall germination responses of each cohort. The seeds were carefully selected from those with intact coats. A preliminary cutting test allowed the determination of $11 \mathrm{mg}$ as the threshold mass for fully developed seeds to be used in the experiments. Unwinged seeds were weighed by means of a semi-micro balance to the nearest $10^{-2} \mathrm{mg}$.

\section{Morphometric Analyses}

Morphometric analyses were performed on 125-150 seeds per fire cohort (125 from FC0, 125 from FC1, and 150 from
FC2), for a total of 400 seeds. Each seed was photographed in its coronal/abaxial plane (Figure 2A; see Kolotelo, 1997 and Terskikh et al., 2005) at $2.5 \times$ magnification using an optical microscope (Dialux 20, Leitz, Germany) equipped with a CoolSnap K4 camera (Photometrics, USA). The coronal shape of each seed was then numerically derived from the digital images of the seeds through an ad hoc computer script (unpublished data) developed for the $\mathrm{R}$ programming environment ( $\mathrm{R}$ Core Team, 2014), based on the codes reported in Claude (2008). The script (i) imported the binary images of the seeds (threshold performed using the ImageJ $1.43 \mathrm{u}$ software package), (ii) derived the Cartesian coordinates of each pixel on the contour of the seed, (iii) calculated the centroid of the contour points, (iv) rotated the point set around the centroid, and (v) compressed the information by storing the length of 36 vectors, from the centroid to the contour points, spread by $10^{\circ}$ from each other. The shape of the seeds was then defined by 36 variables, each one corresponding to the length of a radius.

The seeds were carefully uncoated from the micropylar end using hand cutters and weighed again. Uncoated seeds were free-hand cross-sectioned with a razor blade (Figure 2B), obtaining three to five thin sections, which were mounted on a glass slide and photographed with the aforementioned apparatus. The digital images were then analyzed with the free software package ImageJ $1.43 \mathrm{u}$ (http://rsb.info.nih.gov/ij/index. html), fitting their perimeters with polylines. The section with the largest surface was selected and used for the measurement 

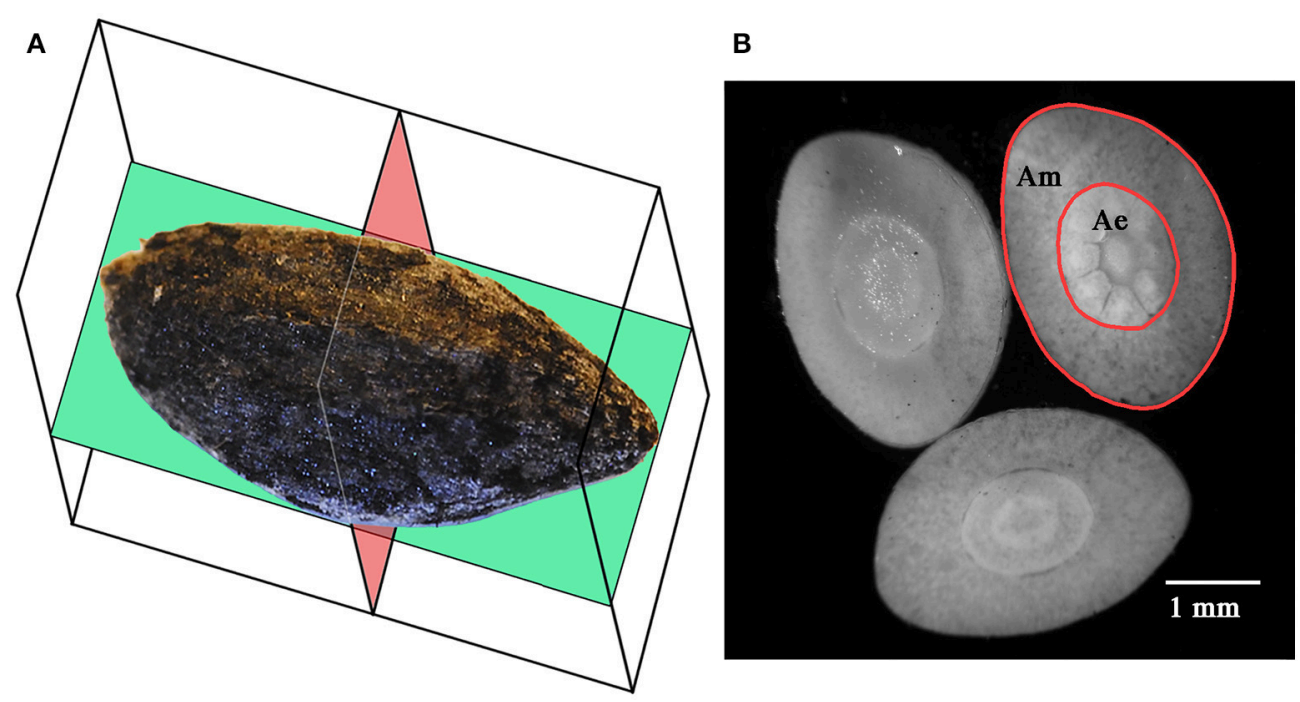

FIGURE 2 | Coronal (green) and axial (red) sectional planes of Aleppo pine seeds (A). Axial sections of an Aleppo pine seed showing the megagametophyte (Am) and the embryo (Ae) (B). Seed in (A) is positioned on its adaxial side.

of the section area of the embryo with and without the megagametophyte. The area of the megagametophyte and the mass of the coat were calculated as the difference between the previous measurements.

\section{Germination Tests}

Germination tests involved experiments under different osmotic potentials $\left(\Psi_{\pi}\right)$ and $\mathrm{pH}$. Seeds were germinated in $9 \mathrm{~cm}$ disposable Petri dishes over four layers of filter paper wetted with $10 \mathrm{ml}$ of test solution. In order to minimize $\Psi_{\pi}$ and $\mathrm{pH}$ variations over time, seeds were transferred to freshly prepared dishes every 3 days. Petri dishes were placed in the dark in a germination chamber set on a $13 \mathrm{~h}-15^{\circ} \mathrm{C}: 11 \mathrm{~h}-25^{\circ} \mathrm{C}$ cycle. This experimental setting aimed to reproduce the environmental conditions experienced by seeds in the field during germination: seeds buried in the dark under $2-3 \mathrm{~cm}$ of black post-fire substrate (A. Saracino, unpublished results), at the night:day soil temperatures previously recorded during seedling emergence from October to November (Saracino et al., 1993).

In order to simulate the variable conditions of the post-fire field substrates (Bodí et al., 2014), the germination tests involved six $\Psi_{\pi}$ levels between 0 and $-1.2 \mathrm{MPa}$, and six $\mathrm{pH}$ levels between 6 and 11. Mannitol solutions were employed for the $\Psi_{\pi}$ germination tests to avoid the toxic effect of polyethylene glycols on the germination of $P$. halepensis seeds (Leshem, 1966), whereas different buffered solutions were employed in the $\mathrm{pH}$ germination tests ( $\mathrm{pH}$ 6.0: MES $50 \mathrm{mM}$; $\mathrm{pH}$ 7.0: MOPS $50 \mathrm{mM}$; pH 8.0 or $\mathrm{pH}$ 9.0: TRIS $50 \mathrm{mM}$; $\mathrm{pH} 10.0$ or $\mathrm{pH} 11.0$ : CAPS $50 \mathrm{mM}$ ). Each treatment was replicated five times on batches of 20 seeds. Germinated seeds were counted daily and removed as soon as radicles had protruded until the 28th day after seeding. Ungerminated seeds were then tested for viability by means of tetrazolium tests to refer the germination percentage to the total of viable seeds.

\section{Data Analysis}

The overall differences among the fire cohorts in the morphological traits of the seeds were inferred through a multivariate analysis of variance (MANOVA). The mass of the uncoated seeds $(\mathrm{Mu})$, the mass of the coat $(\mathrm{Mc})$, the area of the megagametophyte (Am), the area of the embryo (Ae), and the area of the coronal plane (Ac), were included in the model as dependent variables. A generalized canonical discriminant analysis (CVA) was used to evaluate the contribution of the biometrical traits in differentiating the seeds among the three cohorts. Moreover, a MANOVA and a CVA were performed to analyse the variations in seed shape in relation to the number of fires, using the 36 radii defining the contour of the seeds as dependent variables and the fire cohort as the fixed factor. The relationship between each morphometric parameter and fire history was assessed through linear mixed models using the number of fires and the tree size (both height and diameter at breast height as descriptors of plant ontogenetic stage) as fixed factors and the mother plant as a random factor. The significance of fire history and tree size was then evaluated using a Kenward-Roger adjusted $F$-test.

Cumulative germination percentages $\left(\mathrm{G}_{f}\right)$ and mean germination time (MGT), defined as the time when half of the viable seeds had germinated, were selected as descriptors of seed germination performance. $\mathrm{G}_{f}$ values were logit-transformed, according to Warton and Hui (2011) using the equation:

$$
G_{f}=\left(G_{f}+\varepsilon\right) /\left(1-G_{f}+\varepsilon\right)
$$

where $\varepsilon=0.01$ to obtain a normal distribution.

The relation between $\mathrm{G}_{f}$ or MGT with fire history and tree age was evaluated through ridge regression using the number of fires, tree age and $\Psi_{\pi}$ or $\mathrm{pH}$ as predictors. Tree age, rather than tree 
size, has been used in analysing germination data, since in the experiments, seeds from various plants were pooled together.

The ridge regression technique was chosen in relation to its L2 regularization, avoiding the shrinkage to zero of the weakest predictors, and to its usefulness in dealing with non-orthogonal problems (Hastie et al., 2009). Moreover, the predictors were scaled to mean zero and unit variance to allow their importance ranking in predicting $\mathrm{G}_{f}$ and MGT. The penalty parameter $(\lambda)$ for model selection was chosen using the method proposed by Cule and De Iorio (2012).

The relationship between $\mathrm{G}_{f}$ or MGT and $\Psi_{\pi}$ or pH was then modeled separately for the three fire cohorts using linear models and the differences in the slopes were tested with $z$-tests. All analyses and graphics were performed with the stats, lme4, lmtest, nortest, candisc, pbkrtest, ridge, and vioplot packages in R 3.1.1 (R Core Team, 2014).

\section{RESULTS}

Seeds from the three fire cohorts were differentiated in a multivariate context based on their size and mass (Pillai's trace $=0.36, P<0.001$ ), with a clear separation of FC2 seeds from those of the other two cohorts, the confidence circle of which partially overlapped. Morphometric traits differentially contributed to separate the three fire cohorts according to the decreasing order of the vector length: $\mathrm{Ac}, \mathrm{Mu}, \mathrm{Ae}, \mathrm{Mc}$, and Am (Figure 3A). The number of fires was significant in predicting Ac $(P<0.05)$ and $\mathrm{Mu}(P=0.05)$, whereas neither the number of fires nor the tree size were significant in predicting the other morphometric traits (Table 2). The variation in Ac and, to a lesser extent, in $\mathrm{Mu}$ among the cohorts is highlighted also in Figure 3B, showing the distribution of each morphometric trait in the three fire cohorts through violin plots. Seed shape was significantly affected by the number of fires (Pillai's trace $=0.54$, $P<0.001$ ) (Figure 4A), with an anisotropic increase in the seed coronal section (Figure 4B). Ridge regression results are reported in Table 3. In the $\Psi_{\pi}$ experiment, all predictors, namely number of fires, tree size and $\Psi_{\pi}$, were significant in predicting the mean germination times, with the absolute value of the scaled coefficients $(|\beta|)$ decreasing in the order tree age $>$ fire number $>\Psi_{\pi}$. Conversely, tree age had the highest $|\beta|$ in the cumulative germination model and lower values were associated to $\Psi_{\pi}$ and then fire number, with $P$-values greater than the $5 \%$ confidence limit. Overall, FC1 showed better germination in the $\Psi_{\pi}$, with higher $\mathrm{G}_{f}$ and lower MGT than the other two fire cohorts (Figures 5A,C). In the $\mathrm{pH}$ experiment, the number of fires had the highest $|\beta|$ both in the cumulative germination and in the mean germination time models. In the former, tree age $|\beta|$ was associated with a $P$-value greater than the $5 \%$ confidence limit. Furthermore, the number of fires determined an increase in $\mathrm{G}_{f}$ with a change in the slope in relation to $\mathrm{pH}$, and a monotonic decrease in MGT (Figures 5B,D). Differences in the slopes of the analyzed parameters were observed only in the $\mathrm{pH}$ experiment for cumulative germination. Specifically, the slope decreased at increasing fire passages from -0.063 in FC0 to -0.001 in FC2 (Figure 5B). The slopes were significantly $(P<0.001$ and $P<0.05$, respectively) different from 0.0 in FC0 and FC1, but not in FC2.

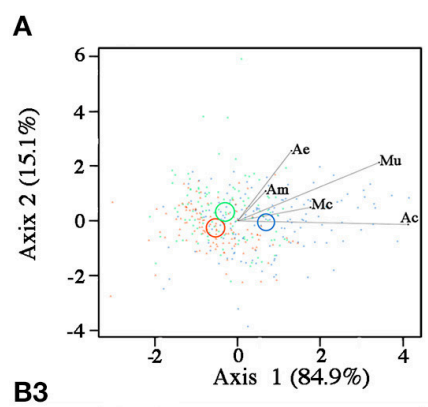

B1

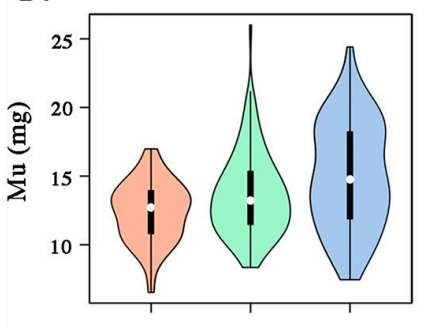

B4
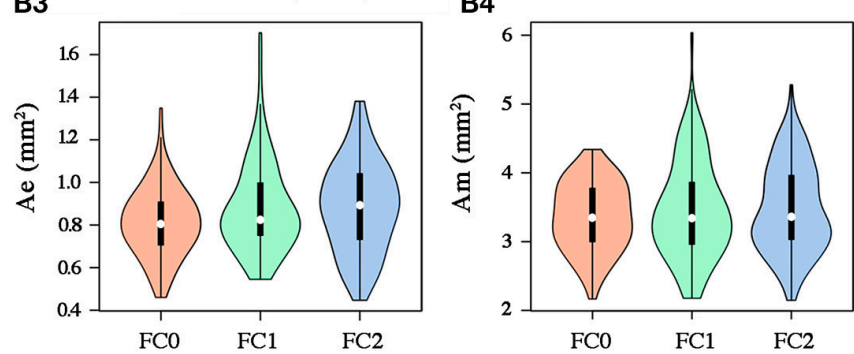

B2

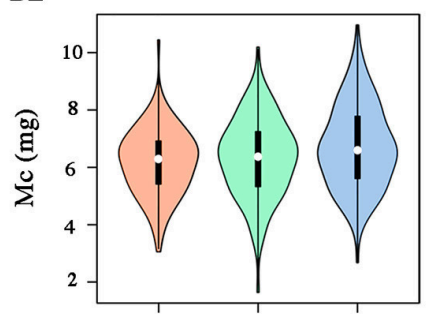

B5

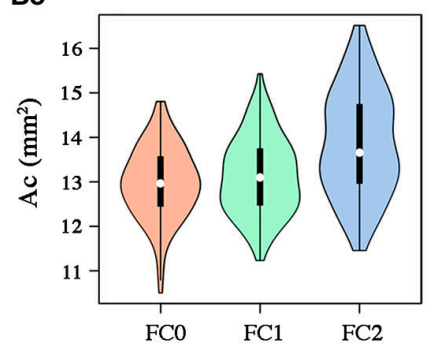

FIGURE 3 | (A) Canonical variate analysis on seed morphometric traits (Mu, mass of the uncoated seed; Mc, mass of the coat; Ae, area of the embryo; Am, area of the megagametophyte; Ac, area of the coronal section of the seed). Fire cohorts are coded in different colors (FC0: red; FC1: green; FC2: blue). Vectors indicate the strength and influence of specific morphometric traits on point location relative to canonical axis 1 and axis 2 . Confidence circles (for $\alpha=0.05$ ) are also shown, enclosing the true mean of each group at the 95\% confidence level and highlighting significant differences among groups in case of no overlap. (B) Violin plots for seed morphometric traits: [Mu: B1; Mc: B2; Ae: B3; Am: B4; Ac: B5]. White circles, black rectangle and upper and lower lines for each violin represent the median, the interquartile range and the upper and lower whisker, respectively. Colored bands represent the kernel density plot. 
TABLE 2 | Summary of the linear mixed models for each morphometric trait (X: Ac, area of the coronal plane; Mu, mass of the uncoated seeds; Mc, mass of the coat; Am, area of the megagametophyte; Ae, area of the embryo) including fire number (left) and tree height (right) as predictors.

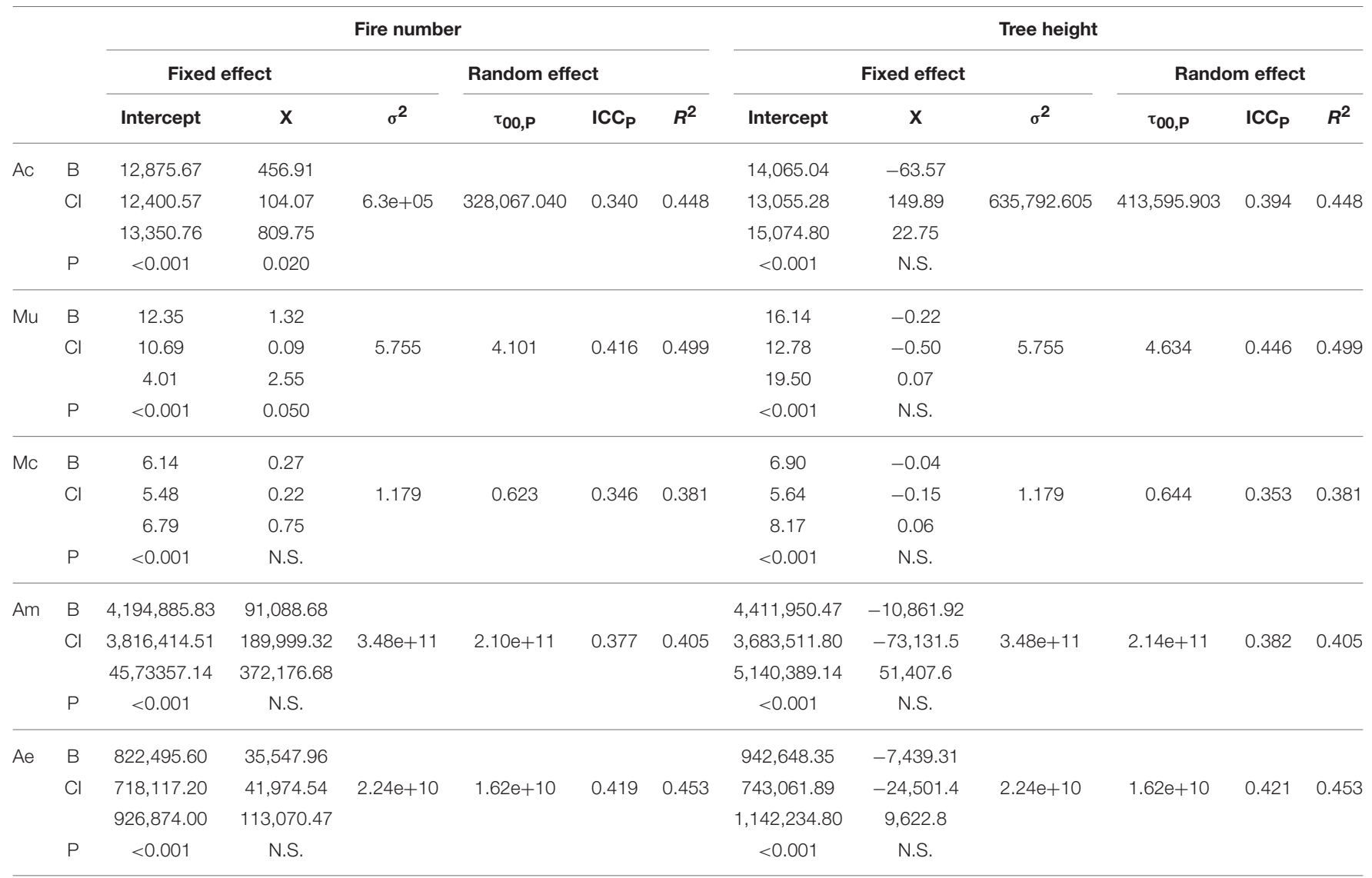

B, coefficient value; Cl, 95\% confidence interval (upper and lower values represent the lower and upper limit, respectively); $P, P$-value; $\sigma^{2}$, within-group (residual) variance; $\tau_{00, P}$, between-group-variance; ICC ${ }_{p}$, intraclass correlation coefficient; $R^{2}$, coefficient of determination.
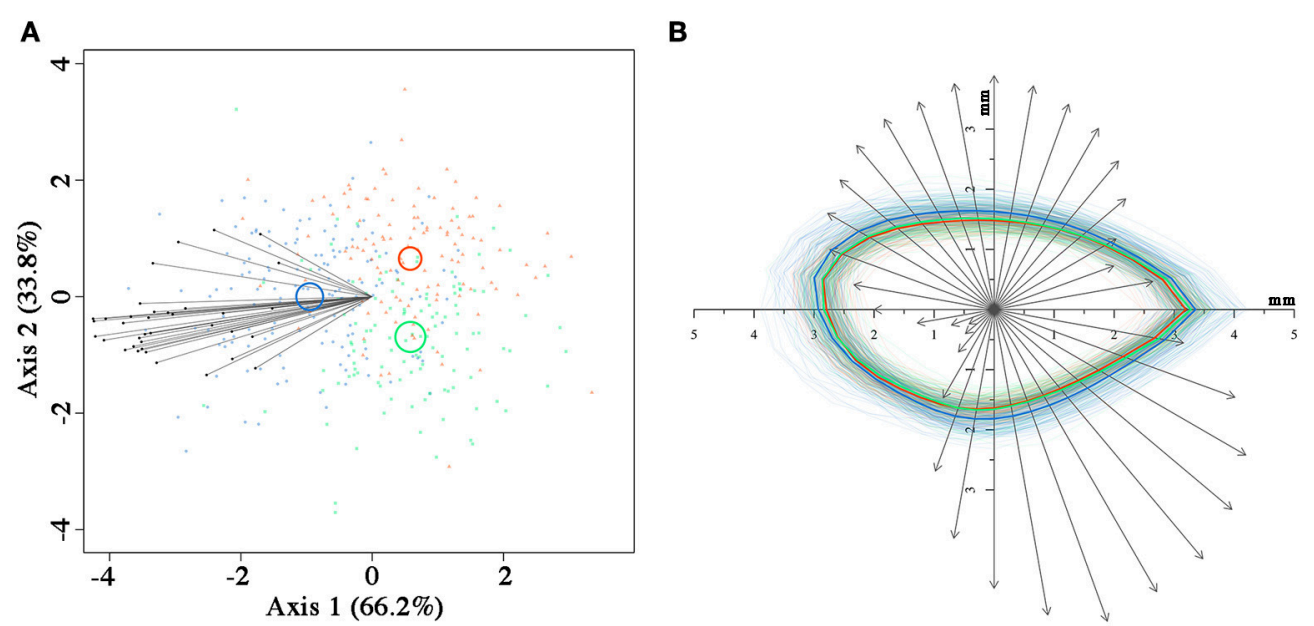

FIGURE 4 | Canonical variate analysis (A) on seed coronal shape using the 36 radii length data, with confidence circles (for $\alpha=0.05$ ) highlighted. Superimposition (B) of the contour of each seed from the three fire cohorts and of the vectors relative to the first canonical axis from (A). The mean contour for each fire cohort is highlighted with thicker lines. In both (A,B), fire cohorts are coded in different colors (FCO: red; FC1: green; FC2: blue). 


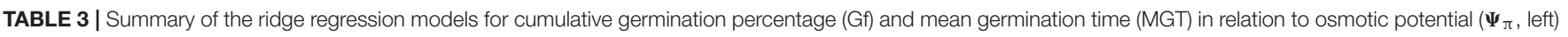
and $\mathrm{pH}$ (right) as well as fire number and tree age.

\begin{tabular}{|c|c|c|c|c|c|c|c|c|c|}
\hline & & Intercept & $\Psi_{\pi}$ & Fire number & Tree age & Intercept & $\mathrm{pH}$ & Fire number & Tree age \\
\hline \multirow[t]{6}{*}{$\mathrm{G}_{f}$} & $\beta_{\mathrm{ns}}$ & 2.432639 & -0.056 & 0.020 & -0.004 & 2.159004 & -0.122 & 0.269 & -0.007 \\
\hline & $\beta$ & & -0.208 & 0.158 & -1.140 & & -2.308 & 2.491 & -2.402 \\
\hline & s.e.m. & & 0.629 & 0.424 & 0.424 & & 1.054 & 0.900 & 0.900 \\
\hline & $t$ & & 0.331 & 0.373 & 2.691 & & 2.189 & 2.766 & 2.668 \\
\hline & $P$ & & N.S. & N.S. & $<0.01$ & & $<0.05$ & $<0.01$ & $<0.01$ \\
\hline & $\lambda$ & \multicolumn{4}{|c|}{0.7559479} & \multicolumn{4}{|c|}{0.1389254} \\
\hline \multirow[t]{6}{*}{ MGT } & $\beta \mathrm{ns}$ & 5.96820 & 3.228 & 2.699 & 0.088 & 16.34290 & 0.595 & -1.248 & 0.013 \\
\hline & $\beta$ & & 12.078 & 20.905 & 24.991 & & 11.214 & -11.565 & 4.274 \\
\hline & s.e.m. & & 0.974 & 2.457 & 2.457 & & 3.178 & 3.544 & 3.544 \\
\hline & $t$ & & 12.401 & 8.509 & 10.172 & & 3.529 & 3.263 & 1.206 \\
\hline & $P$ & & $<0.001$ & $<0.001$ & $<0.001$ & & $<0.001$ & $<0.01$ & N.S. \\
\hline & $\lambda$ & \multicolumn{4}{|c|}{0.02121095} & \multicolumn{4}{|c|}{0.08340478} \\
\hline
\end{tabular}

$\beta_{n s}$, non-scaled coefficient value; $\beta$, scaled coefficient value; s.e.m., standard error of $\beta ; t, t$-value associated to $\beta ; P, P$-value; $\lambda$, penalty parameter.

\section{DISCUSSION}

\section{Seed Morphology}

Differences in seed morphology among the three cohorts were highlighted in a multivariate context, with coronal area, the mass of uncoated seed and embryo size as the morphometric traits that contributed more to separate the three fire cohorts. The differentiation among cohorts is primarily related to the coronal area and the mass of the uncoated seeds, indicating an effect of the number of fires on these traits. Although variations in seed coronal area in relation to age/ontogenetic stage of the mother plants could not be definitively excluded, our result strongly suggests that the increase in coronal area, and to a lesser extent in other morphometric traits, is related to the fire history rather than to tree age. Indeed, young pine trees should produce fewer and smaller seeds than older trees in the same environment (Thanos and Daskalakou, 2000), whereas the opposite was observed in our study, supporting the hypothesis that seed size and shape are traits positively affected by fire. Our results could not confirm the influence of fire passages on the size of the megagametophyte and seed coat, which are considered important in the fire ecology of this species (Salvatore et al., 2010). Conversely, embryo size contributed to separate the three fire cohorts, and slightly increased from FC0 to FC2. Such an occurrence can be explained considering the importance of seed germination kinetics on seedling survival, which is a function of the embryo rather than of the megagametophyte. Indeed, larger embryos can germinate earlier (Vivrette, 1995) and overcome intraspecific competition for space, rather than nutrients, which are usually not limiting in post-fire substrates. Improved competitive advantage and seedling survival in larger Aleppo pine seeds, attributed to the higher number of cotyledons, were also reported by Daskalakou and Thanos (2010). Crown ontogeny may instead play a role in determining the higher variability in seed morphological traits exhibited by the younger fire cohort, since we collected cones on both stems and branches.
The variation in seed traits is often involved in plant evolution: in obligate seeders, seed-related traits like shape and mass (Weiher et al., 1999) usually have a major role in both post-fire seedling distribution and establishment (Hammill et al., 1998; Gómez-González et al., 2011, 2016; Shryock et al., 2014; Ruprecht et al., 2015; Jiménez-Alfaro et al., 2016). In our case the observed anisotropic increase in seed size, which leads to a change in seed shape, might affect a number of processes like dispersion, penetration and persistence in post-fire substrates, in which also seed wing traits may be involved. However, we cannot definitively exclude a non-adaptive age dependent plasticity in these traits. Therefore, this topic deserves further investigation.

\section{Germination Patterns}

In our study, the patterns of seed germination varied in relation to fire history, with seeds from FC2 exhibiting a greater ability to cope with the constraints imposed by the ash bed in the elective post-fire germination microsite of the crown projection area. Specifically, the number of fires improved seed tolerance to alkaline $\mathrm{pH}$ more than to the osmotic potential, both in terms of germination percentage and mean germination time. By contrast, the age of mother plants seems to have a greater effect on the germination performances under osmotic constraints. Cumulative germination showed the clearest responses, gradually shifting from marked inhibition at alkaline $\mathrm{pH}$ in FC0 seeds to a neutral response in FC2 seeds. Wood ashes of coniferous species typically reach $\mathrm{pH}$ values up to 11 (Raison, 1979; Thomas and Wein, 1990; Henig-Sever et al., 1996), which can inhibit germination. Indeed, HenigSever et al. (1996) considered the high soil $\mathrm{pH}$ induced by post-fire ash accumulation as the main abiotic factor controlling Aleppo pine forest regeneration, despite the promoting effect of nitrate and ammonium availability on seed germination (HenigSever et al., 2000). In addition, leaching by rain is usually not sufficient to produce a favorable seedbed before the occurrence of seed fall, as demonstrated in P. banksiana stands (Thomas 

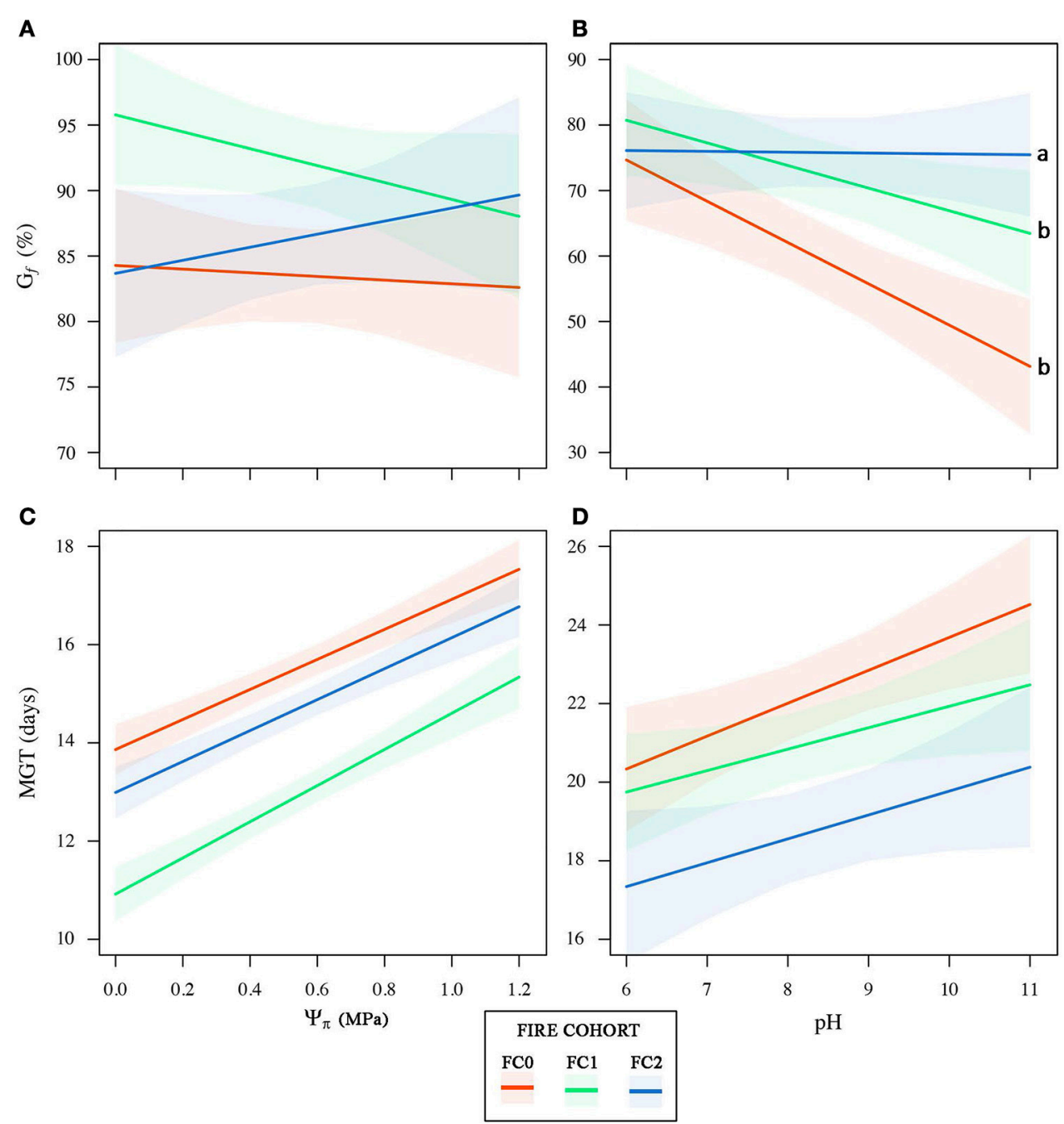

FIGURE 5 | Cumulative germination percentage $\left(\mathrm{G}_{f}\right)$ and mean germination time (MGT) as a function of the osmotic potential ( $\Psi \pi$, A,C) and pH (B,D) gradients for the three fire cohorts. 95\% confidence bands for the linear models for each fire cohort are shown. Letters indicate significant differences between regression slopes according to $z$-test.

and Wein, 1994). The neutral response to $\mathrm{pH}$ of FC2 seeds suggessts that, at least in the short term, fire recurrence does not constrain the reproduction ability. Actually, it seems that after two repeated stand-replacing crown fires, Aleppo pine has the same, or even a better, capability to overcome the main abiotic constraint for the germination of seeds in post-fire substrates. Total germination under the osmotic constraint is above $80 \%$ in all fire cohorts, and age is the most important trait in predicting this behavior. This evidence suggests that fire frequency affects reproductive performance to a lesser extent than osmotic stress and is consistent with previous work which considers this environmental constraint more related to drought than to fire regimes (Falusi et al., 1983; Thanos and Skordilis, 1987). As such, in our case the high resistance to osmotic stress could be considered an adaptation to the semi-arid climate of the area. However, the potential interaction between drought and osmotic potential deserves further investigation, since Aleppo pine seed germination occurs in autumn-winter, when soil is rewetted by precipitation.

The mean germination time pattern in relation to the osmotic potential was non-linear in relation to fire history, with FC1 seeds consistently germinating earlier than the others. This pattern may be related to the length of fire intervals (about $50 \mathrm{y}$ for FC1 vs. $24 \mathrm{y}$ for FC2). Indeed, mother plants of FC1 seeds were recruited on ash beds deeper and richer in soluble cations (Alifragis et al., 2001) than those of FC2 seeds, due to the higher litter and biomass accumulation during the FC1 life span. These features increase both fire intensity and the amount of ash deposited (Cerdà and Doerr, 2008; Bodí et al., 2014), suggesting an involvement of fire also in determining seed resistance to osmotic stresses. 
Experimental results on the effects of the osmotic potential on Aleppo pine seed germination vary in relation to seed provenance (Thanos and Daskalakou, 2000). Henig-Sever et al. (1996) pointed out that osmotic potential only marginally affects the germination performance, and Thanos and Skordilis (1987) reported that Aleppo pine can show remarkable germination rates under osmotic stress attaining $\Psi_{\pi}>-1.46 \mathrm{MPa}$. Conversely, Falusi et al. (1983) showed that $\Psi_{\pi}$ ranging from -0.2 to $-0.6 \mathrm{MPa}$ can reduce germination rates and root growth in some provenances. However, literature results do not resolve the concomitant fire history and seed provenance effects, which limit the reach of the comparisons with our findings. It is well documented that repeated stand-replacing fires reduce the vegetative and reproductive fitness of Aleppo pine by delaying the onset of cone production, reducing the cone crop per tree and the number of reproductive pines (Eugenio et al., 2006; Espelta et al., 2008). In addition, future scenarios in the Mediterranean Basin predict an increase in fire frequency (Mouillot et al., 2002; Pausas and Keeley, 2009) due to a reduction in rainfall (IPCC, 2013). According to our findings, it seems that, at least in the germination phase, fire recurrence does not constrain the reproduction ability of $P$. halepensis due to production of seeds with increased tolerance to the constraints imposed by the ash bed. Instead, the neutral response in relation to $\mathrm{pH}$ entails the absence of ash $\mathrm{pH}$ constraint on the reproductive niche of the Aleppo pine cohort experiencing repeated fires, ensuring maintenance of fitness and population persistence in fire-prone areas. These changes should occur under several mechanisms implying genetic selection, at the germination stage, of seeds with better germination performance on ash beds. Under the genetic selection hypothesis, the ash layer selective pressure on seed germination would drive population adaptation to repeated fires, with future plants differentially recruited in relation to morphological, physiological or biochemical seed traits, and the eventual fixation of fire-related traits. As known, the environment can also provide adaptive transgenerational plasticity. This is often related to changes to seed provisioning and biochemistry as well as epigenetic mechanisms (reviewed by Herman and Sultan, 2011). They are environmentally sensitive and heritable, and thus play a key role in regulating transgenerational effects following plant stress conditions (Jablonka and Raz, 2009). In this perspective,

\section{REFERENCES}

Agee, J. K. (1998). "Fire and pine ecosystems," in Ecology and Biogeography of Pinus, ed D. M. Richardson (Cambridge: Cambridge University Press), 193-218.

Alifragis, D., Smiris, P., Maris, F., Kavvadiaa, V., Konstantinidou, E., and Stamou, N. (2001). The effect of stand age on the accumulation of nutrients in the aboveground components of an Aleppo pine ecosystem. For. Ecol. Manage. 141, 259-269. doi: 10.1016/S0378-1127(00)00334-0

Bodí, M. B., Martin, D. A., Balfour, V. N., Santín, C., Doerr, S. H., Pereira, P., et al. (2014). Wildland fire ash: production, composition and eco-hydro-geomorphic effects. Earth Sci. Rev. 130, 130-127. doi: 10.1016/j.earscirev.2013.12.007

Cerdà, J., and Doerr, S. H. (2008). The effect of ash and needle cover on surface runoff and erosion in the immediate post-fire period. Catena 74, 256-263. doi: 10.1016/j.catena.2008.03.010 an alternative explanation of the differences observed among the fire cohorts could be related to short-term adaptation due to epigenetic modifications, e.g., post-translational changes of histone proteins, cytosine DNA methylation, action of small RNA (Danchin et al., 2011). These modifications are heritable, can all cause changes in gene expression and, as recently reported by Yakovlev et al. (2012), may represent an efficient mechanism to survive under changing environments. The age-dependent responses highlighted in this work can be considered positive traits to cope with frequent fire regime. Further studies are required to assess if they are phenotypic traits varying with growth and development, or if they are the result of long-term adaptation of this species to a fire prone environment.

We are confident that this work may open many research fronts, with further research involved in clarifying whether these observed short term responses are able to drive the local adaptation of new ecotypes, eventually allowing the maintenance of the reproduction ability of $P$. halepensis populations under recurrent fire regime.

\section{AUTHOR CONTRIBUTIONS}

AS conceived and coordinated the study. AB participated in the design and performed the statistical analysis with input of SR. AB, $\mathrm{AM}, \mathrm{EA}$, and SC carried out experimental work. AS, AB, and EA wrote the main manuscript. All authors contributed to discussing and interpreting the data at all stages.

\section{ACKNOWLEDGMENTS}

We are grateful to the Ufficio Territoriale per la Biodiversità di Martina Franca (TA) for allowing sampling in the study site and the Forest Service Posto Fisso Marina di Ginosa bis for its assistance with logistics. We also thank Dr. F. Cona, Dr. A. Franza, Dr. G. Guida, Dr. G. Melchionna, and Dr. L. Bellino for their technical assistance. The work was dedicated to the memory of Vincenzo Giove (Bicienz) who spent many early mornings in the heat of summer collecting Aleppo pine seeds on ash beds with the lead author. Manuscript has been significantly improved thanks to the useful suggestions of two reviewers.
Claude, J. (2008). Morphometrics with R. New York, NY: Springer.

Climent, J., Prada, M. A., Calama, R., Chambel, M. R., de Ron, D. S., and Alía, R. (2008). To grow or to seed: ecotypic variation in reproductive allocation and cone production by young female Aleppo pine (Pinus halepensis, Pinaceae). Am. J. Bot. 95, 833-842. doi: 10.3732/ajb.2007354

Cule, E., and De Iorio, M. (2012). A semi-automatic method to guide the choice of ridge parameter in ridge regression. arXiv:1205.0686v061

Danchin, E., Charmantier, A., Champagne, F. A., Mesoudi, A., Pujol, B., and Blancet, S. (2011). Beyond DNA: integrating inclusive inheritance into an extended theory of evolution. Nat. Rev. Genet. 12, 475-486. doi: $10.1038 / \operatorname{nrg} 3028$

Daskalakou, E. N., and Thanos, C. (1996). Aleppo pine (Pinus halepensis) postfire regeneration: the role of canopy and soil seed banks. Int. J. Wildland Fire 6, 59-66. doi: 10.1071/WF9960059 
Daskalakou, E. N., and Thanos, C. A. (2010). Postfire seedling dynamics and performance in Pinus halepensis Mill. populations. Acta Oecol. 36, 446-453. doi: 10.1016/j.actao.2010.05.001

Dumontet, S., Dinel, H., Scopa, A., Mazzatura, A., and Saracino, A. (1996). Post-fire soil microbial biomass and nutrient content of a pine forest soil from a dunal Mediterranean environment. Soil Biol. Biochem. 28, 1467-1475. doi: 10.1016/S0038-0717(96)00160-5

Espelta, J. M., Verkaik, I., Eugenio, M., and Lloret, F. (2008). Recurrent wildfires constrain long-term reproduction ability in Pinus halepensis Mill. Int. J. Wildland Fire 17, 579-585. doi: 10.1071/WF07078

Eugenio, M., Verkaik, I., Lloret, F., and Espelta, J. M. (2006). Recruitment and growth decline in Pinus halepensis populations after recurrent wildfires in Catalonia (NE Iberian Peninsula). For. Ecol. Manage. 231, 47-54. doi: 10.1016/j.foreco.2006.05.007

Falusi, M., Calamassi, R, and Tocci, A. (1983). Sensitivity of seed germination and seedling root growth to moisture stress in four provenances of Pinus halepensis Mill. Silvae Genet. 32, 4-9.

FAO (1997). Directory of Seed Sources of the Mediterranean Conifers. Rome: FAO, Forest Resources Division, Forestry Department. [WWW document]. Available online at: http://www.fao.org/DOCREP/006/AD112E/AD112E00. HTM (Accessed 2 October, 2016).

Gómez-González, S., Ojeda, F., Torres-Morales, P., and Palma, J. E. (2016). Seed pubescence and shape modulate adaptive responses to fire cues. PLoS ONE 11:e0159655. doi: 10.1371/journal.pone.0159655

Gómez-González, S., Torres-Díaz, C., Bustos-Schindler, C., and Gianoli, E. (2011). Anthropogenic fire drives the evolution of seed traits. Proc. Natl. Acad. Sci. U.S.A. 108, 18743-18747. doi: 10.1073/pnas.1108863108

Goubitz, S., Nathan, R., Roitemberg, R., Shmida, A., and Ne'eman, G. (2004). Canopy seed bank structure in relation to: fire, tree size and density. Plant Ecol. 173, 191-201. doi: 10.1023/B:VEGE.0000029324.40801.74

Hammill, K. A., Bradstock, R. A., and Allaway, W. G. (1998). Post-fire seed dispersal and species re-establishment in Proteaceous heath. Aust. J. Bot. 46, 407-419. doi: 10.1071/BT96116

Hastie, T., Tibshirani, R., and Friedman, J. (2009). The Elements of Statistical Learning. New York, NY: Springer-Verlag. doi: 10.1007/978-0-387-84858-7

Henig-Sever, N., Eshel, A., and Ne'eman, G. (1996). pH and osmotic potential of pine ash as post-fire germination inhibitors. Physiol. Plant. 96, 71-76.

Henig-Sever, N., Eshel, A., and Ne'eman, G. (2000). Regulation of the germination of Aleppo pine (Pinus halepensis) by nitrate, ammonium, and gibberellin, and its role in post-fire regeneration. Physiol. Plant. 108, 390-397. doi: 10.1034/j.1399-3054.2000.t01-1-100408.x

Herman, J. H., and Sultan, S. E. (2011). Adaptive transgenerational plasticity in plants: case studies, mechanisms, and implications for natural populations. Front. Plant Sci. 2:102. doi: 10.3389/fpls.2011.00102

IPCC (2013). Climate Change 2013: The Physical Science Basis. Contribution of Working Groups I to the Fifth Assessment Report of the Intergovernmental Panel on Climate Change. Cambridge, New York: Cambridge University Press.

Jablonka, E., and Raz, G. (2009). Transgenerational epigenetic inheritance: prevalence, mechanisms, and implications for the study of heredity and evolution. Q. Rev. Biol. 84, 131-176. doi: 10.1086/598822

Jiménez-Alfaro, B., Silveira, F. A., Fidelis, A., Poschlod, P., and Commander, L. E. (2016). Seed germination traits can contribute better to plant community ecology. J. Veg. Sci. 27, 637-645 doi: 10.1111/jvs.12375

Keeley, J. E., and Zedler, P. H. (1998). "Evolution of life histories in Pinus," in Ecology and Biogeography of Pinus, ed D. M. Richardson (Cambridge: Cambridge University Press), 219-250.

Kolotelo, D. (1997). Anatomy and Morphology of Conifer Tree Seed. Forest Nursery Technical Series 1.1. Victoria: British Columbia, Ministry of Forests, Nursery and Seed Operations Branch.

Lamont, B. B., Le Maitre, D. C., Cowling, R. M., and Enright, N. J. (1991). Canopy seed storage in woody plants. Bot. Rev. 57, 277-317. doi: 10.1007/BF02858770

Leshem, B. (1966). Toxic effects of carbowaxes (polyethylen glycols) on Pinus halepensis Mill. seedlings. Plant Soil 24, 322-324. doi: 10.1007/BF02232909

Liodakis, S., Katsigiannis, G., and Kakali, G. (2005). Ash properties of some dominant Greek forest species. Thermochim Acta 437, 158-167. doi: 10.1016/j.tca.2005.06.041

MAF (Ministero dell'Agricoltura e delle Foreste) (1960). Il Libro Nazionale dei Boschi da Seme. Roma, IT: Conifere indigene, MAF, Collana verde 5.
Martín-Sanz, R. C., Santos-del-Blanco, L., Notivol, E., Chambel, M. R., SanMartín, R., and Climent, J. (2016). Disentangling plasticity of serotiny, a key adaptive trait in a Mediterranean conifer. Am. J. Bot. 103, 1582-1591. doi: 10.3732/ajb.1600199

Mitsopoulos, I. D., and Dimitrakopoulos, A. P. (2007). Canopy fuel characteristics and potential crown fire behavior in Aleppo pine (Pinus halepensis Mill.) forests. Ann. For. Sci. 64, 287-299. doi: 10.1051/forest:2007006

Mitsopoulos, I. D., and Dimitrakopoulos, A. P. (2014). Estimation of canopy fuel characteristics of Aleppo pine (Pinus halepensis Mill.) forests in Greece based on common stand parameters. Eur. J. For. Res. 133, 73-79. doi: 10.1007/s10342-013-0740-z

Mouillot, F., Rambal, S., and Joffre, R. (2002). Simulating climate change impacts on fire frequency and vegetation dynamics in a Mediterranean-type ecosystem. Glob. Chang. Biol. 8, 423-437. doi: 10.1046/j.1365-2486.2002.00494.x

Moya, D., Saracino, A., Salvatore, R., Lovreglio, R., de Las Heras, J., and Leone, V. (2008). Anatomic basis and insulation of serotinous cones in Pinus halepensis Mill. Trees 22, 511-519. doi: 10.1007/s00468-008-0211-1

Nathan, R., Safriel, U. N., Noy-Meir, I., and Schiller, G. (1999). Seed release without fire in Pinus halepensis, a Mediterranean serotinous wind-dispersed tree. J. Ecol. 87, 659-669. doi: 10.1046/j.1365-2745.1999.00382.x

Ne'eman, G. (2000). "The effect of burned pine trees on post-fire regeneration," in Ecology, Biogeography and Management of Pinus Halepensis and P. brutia Mediterranean pine Forest Ecosystems, eds G. Ne'eman and L. Trabaud (Leiden: Buckhuys Publishers), 303-319.

Ne'eman, G., Goubitz, S., and Nathan, R. (2004). Reproductive traits of Pinus halepensis in the light of fire-a critical review. Plant Ecol. 171, 69-79. doi: 10.1023/B:VEGE.0000029380.04821.99

Odling-Smee, F. J., Laland, K. N., and Feldman, M. W. (2003). Niche Construction: The Neglected Process in Evolution (Monographs in Population Biology, 37). Princeton, NJ: Princeton University Press.

Paula, S., Arianoutsou, M., Kazanis, D., Tavsanoglu, Ç., Lloret, F., Buhk, C., et al. (2009). Fire-related traits for plant species of the Mediterranean Basin. Ecology 90:1420. doi: 10.1890/08-1309.1

Pausas, J. G. (2015). Evolutionary fire ecology: lessons learned from pines. Trends Plant Sci. 20, 318-324. doi: 10.1016/j.tplants.2015.03.001

Pausas, J. G., and Keeley, J. E. (2009). A burning story: the role of fire in the history of life. BioScience 59, 593-601. doi: 10.1525/bio.2009.59.7.10

Pausas, J. G., and Keeley, J. E. (2014). Evolutionary ecology of resprouting and seeding in fire-prone ecosystems. New Phytol. 204, 55-65. doi: $10.1111 / \mathrm{nph} .12921$

R Core Team (2014). R: A Language and Environment for Statistical Computing. $R$ Foundation for Statistical Computing. Vienna: R Foundation for Statistical Computing.

Raison, R. J. (1979). Modification of the soil environment by vegetation fires, with particular reference to nitrogen transformations: a review. Plant Soil 51, 73-108. doi: 10.1007/BF02205929

Rossi, S., Morin, H., Gionest, F., and Laprise, D. (2017). Inter- and intra-annual patterns of seed rain in the black spruce stands of Quebec, Canada. iForest, 10, 189-195. doi: 10.3832/ifor2145-009

Ruprecht, E., Fenesi, A., Fodor, E. I., Kuhn, T., and Tökölyi, J. (2015). Shape determines fire tolerance of seeds in temperate grasslands that are not prone to fire. Persp. Pl. Ecol. Evol. Syst. 17, 397-404. doi: 10.1016/j.ppees.2015.07.001

Salvatore, R., Moya, D., Pulido, L., Lovreglio, R., López-Serrano, F. R., De las Heras, J., et al. (2010). Morphological and anatomical differences in Aleppo pine seeds from serotinous and non-serotinous cones. New For. 39, 329-341. doi: 10.1007/s11056-009-9174-3

Saracino, A., D’Alessandro, C. M., Maiullari, G., and Leone, V. (2002). "Pattern of resin dripping under Aleppo pines (Pinus halepensis Mill.) of different crown size," in Fire and Biological Processes, eds L. Trabaud and R. Prodon (Leiden: Backhuys Publishers), 291-302.

Saracino, A., Leone, V., and De Natale, F. (1993). Permanent plots for the study of natural regeneration after fire of Pinus halepensis Miller in dunal environment. Annali di Botanica (Roma) 51, 209-217.

Schwilk, D. W., and Ackerly, D. D. (2001). Flammability and serotiny as strategies: correlated evolution in pines. Oikos 94, 326-336. doi: 10.1034/j.1600-0706.2001.940213.x

Shmida, A., Lev-Yadun, S., Goubitz, S, and Ne'eman, G. (2000). “Sexual allocation and gender segregation in Pinus halepensis, P. brutia and P. pinea," in Ecology, 
Biogeography and Management of Pinus halepensis and P. brutia Mediterranean Pine Forest Ecosystems, eds G. Ne'eman and L. Trabaud (Leiden: Backhuys Publishers), 91-104.

Shryock, D. F., De Falco, L. A., and Esque, T. C. (2014). Life-history traits predict perennial species response to fire in a desert ecosystem. Ecol. Evol. 4, 3046-3059. doi: $10.1002 /$ ece 3.1159

Terskikh, V. V, Feurtado, J. A., Ren, C., Abrams, S. R., and Kermode, A. R. (2005). Water uptake and oil distribution during imbibition of seeds of western white pine (Pinus monticola Dougl. ex D. Don) monitored in vivo using magnetic resonance imaging. Planta 221, 17-27. doi: 10.1007/s00425-004-1426-Z

Thanos, C. A., and Daskalakou, E. N. (2000). "Reproduction in Pinus halepensis and P. brutia," in Ecology, Biogeography and Management of Pinus Halepensis and P. brutia Mediterranean Pine Forest Ecosystems, eds G. Ne'eman and L. Trabaud (Leiden: Backhuys Publishers), 79-90.

Thanos, C. A., and Skordilis, A. (1987). The effects of light, temperature and osmotic stress on the germination of Pinus halepensis and P. brutia seeds. Seed Sci. Technol. 15, 163-174.

Thomas, P. A., and Wein, R. W. (1990). Jack pine establishment on ash from wood and organic soil. Can. J. For. Res. 20, 1926-1932. doi: 10.1139/x90-258

Thomas, P. A., and Wein, R. W. (1994). Amelioration of wood ash toxicity and jack pine establishment. Can. J. For. Res. 24, 748-755. doi: 10.1139/x94-099

Vivrette, N. J. (1995). "Distribution and ecological significance of seed-embryo types in Mediterranean climates in California, Chile, and Australia," in Ecology and Biogeography of Mediterranean Ecosystems in Chile, California, and Australia (Ecological studies 108), eds M. T. Kalin Arroyo, P. H. Zedler, and M. D. Fox (New York, NY: Springer Verlag), 274-288. doi: 10.1007/978-1-4612-2490-7_11
Warton, D. I., and Hui, F. K. (2011). The arcsine is asinine: the analysis of proportions in ecology. Ecology 92, 3-10. doi: 10.1890/10-0340.1

Weiher, E., Werf, A., Thompson, K., Roderick, M., Garnier, E., and Eriksson, O. (1999). Challenging Theophrastus: a common core list of plant traits for functional ecology. J. Veg. Sci. 10, 609-620. doi: 10.2307/32 37076

Yakovlev, I., Fossdal, C. G., Skrøppa, T., Olsen, J. E., Jahren, A. H., and Johnsen, Ø. (2012). An adaptive epigenetic memory in conifers with important implications for seed production. Seed Sci. Res. 22, 63-76. doi: 10.1017/S0960258511 000535

Zedler, P. H. (1995). "Fire frequency in Southern California shrublands: biological effects and management options," in Brushfires in California Wildlands: Ecology and Resource Management, eds J. E. Keeley and T. Scott (Fairfield, WA: International Association of Wildland Fire), $101-111$.

Conflict of Interest Statement: The authors declare that the research was conducted in the absence of any commercial or financial relationships that could be construed as a potential conflict of interest.

Copyright (c) 2017 Saracino, Bellino, Allevato, Mingo, Conti, Rossi, Bonanomi, Carputo and Mazzoleni. This is an open-access article distributed under the terms of the Creative Commons Attribution License (CC BY). The use, distribution or reproduction in other forums is permitted, provided the original author(s) or licensor are credited and that the original publication in this journal is cited, in accordance with accepted academic practice. No use, distribution or reproduction is permitted which does not comply with these terms. 